\title{
ARTIGOS
}

\section{CARTOGRAFIAS E CRIAÇÃO DE MUNDOS FICTÍCIOS: LEITURAS OUTRAS NA EDUCAÇÃO GEOGRÁFICA}

\author{
Deyse Cristina Brito Fabrício ${ }^{1}$ \\ Valéria Cazetta ${ }^{2}$
}

\section{Apresentação}

As aulas de Geografia na educação básica geralmente lidam com a cartografia a partir de enfoques que primam por quantificações e posicionamentos, como cálculos de escala e coordenadas de latitude e longitude. Esse tipo de abordagem, que abarca a cartografia cartesiana (SEEMANN, 2011, p. 165), evidencia determinado aspecto das práticas cartográficas, deixando como legado imaginações espaciais (MASSEY, 2008) que estabelecem relações diretas e "transparentes"3 entre espaço e representação.

A necessária e importante abordagem da cartografia pelo viés cartesiano, no entanto, carece de elementos que insiram a criação de mapas em contexto escolar e trabalhem aspectos processuais ligados aos fazeres artístico e performático. Os/as alunos/as estão inseridos no contexto do ciberespaço, em que cada vez mais os mapas são confeccionados por diversos atores, trazendo a possibilidade de estudantes-mapeadores (SEEMANN, 2013, p. 102).

A partir da colaboração de mapeamentos online, de intervenções artísticas, dos jogos de interpretação de personagens etc., todos podem ser cartógrafos. Nessa circunstância, Wood (2003) escreve acerca da extinção do cartógrafo, tal como comumente o conhecemos: um especialista detentor do saber sobre a confecção de mapas, geralmente defendendo os interesses estatais de apropriação e conhecimento do território.

Este texto parte da premissa de que os mapas se diversificaram e estão no contexto dos/as estudantes da educação básica. Verifica-se que há outras cartografias além daquela tradicional encontrada em contexto escolar, como os mapas de jogos e livros relacionados aos mundos fictícios. Por isso, o cotidiano dos/as estudantes é permeado por mapas não convencionais, que podem ser inseridos nas atividades de Geografia.

As representações do espaço abarcam, também, o espaço imaginado. No caso de nossa pesquisa, mapas de jogos estiveram intensamente ligados ao cotidiano dos estudantes, em que a criação de mundos fictícios é recorrente. $\mathrm{Na}$ atualidade há uma série de livros na modalidade da fantasia épica ${ }^{4}$, provocando um boom nas livrarias, principalmente na seção de livros estrangeiros, cujas temáticas mesclam "trilogias mitológicas, vampiros e bruxos" (CURIA, 2012, p. 2).

Nesse arcabouço, os mapas sobre fantasia épica muitas vezes fazem parte do cotidiano dos/as estudantes, a partir de jogos, livros e filmes teenagers (OLIVEIRA, 2016, p. 86), mas

\footnotetext{
${ }^{1}$ Instituto de Geociências/ Universidade Estadual de Campinas. E-mail: deysecbf@gmail.com.

${ }^{2}$ Escola de Artes, Ciências e Humanidades/Universidade de São Paulo. E-mail: vcazetta@usp.br.

${ }^{3}$ A ideia de "transparência" nas representações cartográficas está ligada aos objetivos de mapeamento do Estado, configurados na Modernidade. Bauman (1999, p. 38) nomeia esse processo de "guerra pelo espaço" ao ressaltar a busca por objetividade e padronização na cartografia, que se atrelaria às finalidades utilitárias do Estado, levando a certa "desqualificação" da variedade de mapas confeccionados no período chamado pré-moderno.

${ }^{4}$ A "fantasia épica" é considerada um subgênero literário, tendo como precursor o escritor romântico William Morris, que exerceu influência nas obras de John Ronald Reuel Tolkien. Segundo Souza (2013, p. 64), o subgênero mencionado pode ser caracterizado pelas histórias “impregnadas por um tom grandiloquente, em que há a presença de grandes forças malignas, que precisam ser combatidas pelos heróis guerreiros, em grandiosas batalhas e corajosas façanhas".
} 
acabam sendo desconsiderados a partir de uma única concepção de cartografia, que prioriza os mapas convencionais escolares, encontrados geralmente em livros didáticos. A tarefa de integrar vivências fora da sala de aula às rotinas escolares é um desafio que pode permear as "práticas cotidianas" (ESNAOLA, 2006, p. 12).

Por que não assumir os mapas de mundos fictícios também como a "realidade do aluno", entendendo que podem estar ligados às experiências dos estudantes? O Outro, e aqui incluo os estudantes de educação básica, não pode ser "alijado do direito ao estabelecimento de leituras acerca das espacialidades vividas" (KATUTA, 2005, p. 7241). Dessa maneira, pretendíamos extrapolar a cartografia como "técnica inútil e distante da nossa realidade" (SEEMANN, 2012, p. 29) a partir da confecção de mapas pelos/as estudantes de uma escola pública de Campinas-SP.

Realizamos uma série de atividades voltadas ao primeiro ano do Ensino Médio da Educação Básica, inserindo mapas de mundos fictícios. Para reflexões sobre as atividades junto aos/às alunos/as, estabelecemos entrevistas, delineadas enquanto carto-falas (SEEMANN, 2013). Para este texto escolhemos alguns mapas confeccionados, com suas carto-falas, como forma de apresentação das atividades desenvolvidas, a partir do critério da aderência aos jogos e às formas de narrativa verificadas na atualidade, visando o estabelecimento de um panorama do repertório e do contexto vivenciados pela turma de estudantes.

Também faremos apontamentos sobre o conceito de medievalidade (MACEDO, 2009), por estar relacionado a algumas noções que os/as alunos/as têm sobre a Idade Média, período inserido na ambientação de vários filmes, jogos e livros, que se relacionam à cartografia na criação de mundos e enredos fictícios.

\section{Carto-falas e narrativas não-lineares}

As atividades descritas neste texto contaram com três momentos. Primeiramente apresentamos aos estudantes a proposta de confecção de mapas a partir da mostra de vídeos e mapas relacionados à criação de mundos fictícios, com base na saga "O Senhor dos Anéis" (TOLKIEN, 2001). Como a tarefa da confecção de mapas não é recorrente, principalmente no Ensino Médio, os vídeos e mapas auxiliaram na clareza da proposta perante os/as estudantes. No segundo momento contamos com a confecção de mapas de mundos fictícios pelos/as estudantes, tendo como base folhas em tamanho A4, com uso lápis de cor e giz de cera. Após essa atividade, os/as estudantes foram entrevistados/as a partir da ideia de carto-falas (SEEMANN, 2013).

As carto-falas são abordadas enquanto "sério objeto de pesquisa" (SEEMANN, 2013, p. 101), visando captar narrativas estabelecidas a partir da confecção de mapas e criação de mundos fictícios pelos/as estudantes. Como as narrativas são abertas e múltiplas, no âmbito das carto-falas, Seemann (2013, p. 88) utiliza o termo "histórias da cartografia" propositadamente no plural, afirmando que se referem aos "conteúdos narrativos que chegam à luz do dia nos processos de produção e uso de mapas. " $\mathrm{O}$ autor acrescenta: "não existe uma única versão possível ou uma metanarrativa sobre a cartografia, mas há a coexistência de muitas histórias que se completam, complementam ou contradizem" (SEEMANN, 2013, p. 88).

É justamente a multiplicidade de narrativas estabelecidas que abre espaço para reflexões sobre a forma como se delineia a criação de histórias na atualidade. A tecnologia possibilita uma série de narrativas, caracterizadas por Esnaola (2006, p. 72) como "multiformes", ou seja, que rompem com a linearidade de uma leitura "monolítica e hegemônica da realidade", através de hipertextos.

A linearidade que nasceu com a escrita teve papel determinante no pensamento ocidental e tem, nesta nova realidade em que vivemos, o 
momento de seu declínio, agora que os artefatos tecnológicos - os games permitem mergulhar nas malhas da rede, perder-se e libertar-se dos caminhos proibidos. (MOITA, 2007, p. 58).

Wertheim (2001, p. 163 e seguintes) explica como as concepções de espaço e as relações sociais tendem a sofrer modificações com o advento do ciberespaço, incluindo a criação de mundos fictícios. O ciberespaço potencializou a criação desses mundos a partir de jogos online conhecidos como multiuser domains (MUD). Diferente da leitura de um romance, em que o leitor "encontra um mundo plenamente formado pelo escritor", nos jogos online há um envolvimento ativo dos jogadores "num processo de fabricação de mundo" (WERTHEIM, 2001, p. 171).

Claval (2010, p. 61) escreve: "a atitude que permite construir outros mundos, além deste que é visível, é fundamental para compreender a vida dos grupos". A potencialidade do ciberespaço na criação de mundos virtuais atesta para uma linha mais tênue separando o real e o imaginado, pois jogadores dos MUD adquirem papéis de atores, criando situações, cenários, e alter egos (WERTHEIM, 2001, p. 175). "Denominar é criar, e nos mundos MUD o simples ato de denominar e descrever é tudo que é preciso para gerar um novo alter ego ou "cibereu" (WERTHEIM, 2001, p. 171).

Verificamos narrativas multiformes em histórias e textos produzidos e compartilhados via web (MURRAY, 2003) e, nessas novas abordagens para a literatura, os jogos colaborativos, principalmente aqueles de Role Playing Games (RPG) ${ }^{5}$, ganharam outras dimensões qualitativas pelas facilidades no estabelecimento de conexões com outros/as jogadores/as, proporcionadas pelo ciberespaço.

As conexões das narrativas não-lineares ficam claras quando os mapas acabam assumindo papel importante na concepção dos jogos eletrônicos, que compartilham histórias criadas coletivamente, geralmente pelos próprios jogadores. Por isso, citando os jogos do tipo RPG, além da possibilidade de criação de alter egos, com interações a partir da interpretação de personagens, esses jogos atribuem ao espaço papel fundamental, inclusive no design dos jogos virtuais, ao "definir a forma e o enquadramento da experiência narrativa" (GUERREIRO, 2014, p. 12). Semelhante ideia é proposta por Pearce (2002, apud MUSSA, 2011, p. 2) e Jenkins (2004, apud MUSSA, 2011, p. 2), trazendo a importância do espaço para "arquitetar narrativas" (MUSSA, 2011, p. 2) no sentido da criação de histórias nas quais o espaço participa ativamente, assumindo papel dinâmico (MUSSA, 2011, p. 5). Além disso, podem existir mapas de tesouros ou representações destes mundos fictícios, gerando maiores interações dos jogadores com o espaço, engendrado em determinado enredo:

[...] um jogo pode conter informações "escondidas", tesouros enterrados que se espalham pelos seus diversos mapas e que, quando descobertos ou decifrados, podem vir a acrescentar uma informação a mais sobre aquele mundo, ou apenas despertar mais dúvidas, mas, ainda assim, tendem a significar algo para a estrutura interna do seu universo. (MUSSA, 2011, p. 6).

Essas questões teóricas irão se conectar ao ensino de Geografia, no âmbito da cartografia escolar, indicando elementos que podem estar em transformação no cenário contemporâneo, como a recorrência de mapas no cotidiano dos/as estudantes, referentes à criação de mundos fictícios.

\footnotetext{
${ }^{5}$ A sigla inglesa RPG (Role Playing Games), pode ser traduzida como "jogo de interpretação de personagens". Esse tipo de jogo cria interação entre personagens num cenário fictício, privilegiando a temática da "fantasia medieval" (CARDOSO, 2008, p. 78).
} 
Ao propormos a criação de mapas de mundos fictícios em contexto escolar, utilizamos o recurso das entrevistas enquanto narrativas, em que os estudantes relataram o processo da confecção de seus próprios mapas, abrangendo as carto-falas. Apresentaremos, a seguir, dois tipos de recorrência nas entrevistas: os mapeamentos em jogos e as temáticas medievais.

\section{Carto-falas sobre mapeamentos em jogos}

O aluno José ${ }^{6}$ estabeleceu carto-falas, dizendo que seu mapa foi confeccionado com base no jogo de videogame Destiny ${ }^{7}$ (Figura 1):

"José: - O meu [mapa] foi mais inspirado num jogo que eu jogo com meu pai... Por exemplo este Castelo Desperto é o reino deles...[inaudivel] A Ilha Decaída é onde eles vão para salvar as pessoas... Porque lá tem um bicho... e eles recebem um tipo de chamado para salvar essas pessoas...

Mário: - É um Reino de Proteção?

José: - Sim... tem essa Ilha Caçadora, Terra de Titãs...[inaudivel]

Pesquisadora: - São jogos de videogame?

José: - Esse jogo é de videogame e se chama Destiny...

Pesquisar: - Outras pessoas da classe conhecem esse jogo?

José: - Tem um grande grupo jovem jogando Destiny e pessoas mais velhas... tipo o meu pai e os amigos dele... Um amigo do meu pai lá do Destiny tem 58 anos (grifos nossos) ".

\footnotetext{
${ }^{6}$ Os nomes dos/as estudantes são fictícios.

${ }^{7}$ O jogo Destiny foi desenvolvido pela Bungie, com lançamento em 2014. Abrange versões para jogos online e videogame. A ambientação do jogo, em linhas gerais, contempla a criação de um universo de ficção científica. Fonte: <http://www.techtudo.com.br/tudo-sobre/destiny.html>. Acesso em 17 ago. 2016.
} 


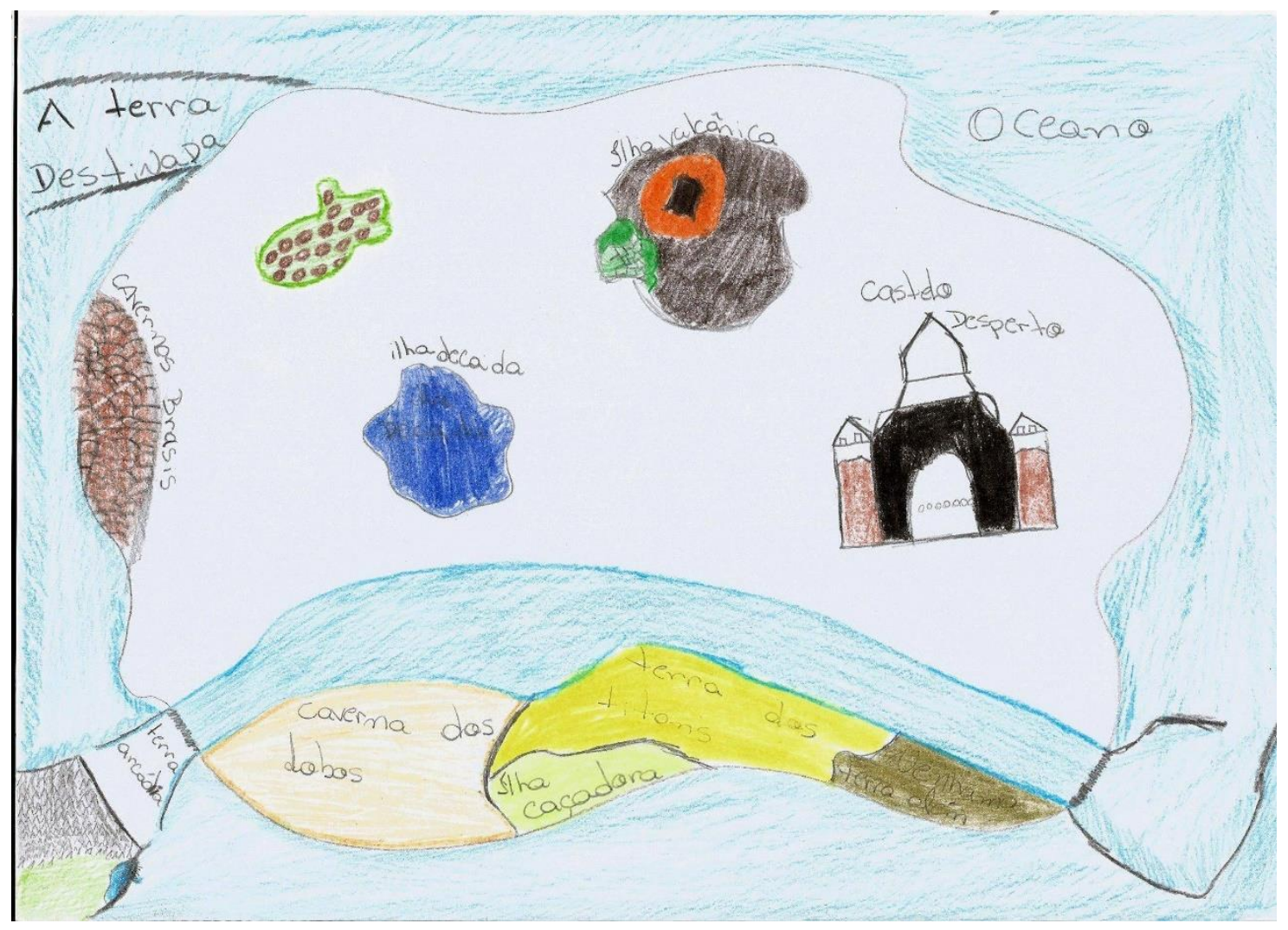

Figura 1 - Mapa do aluno José: "A terra Destinada"

Como é verificado nos jogos online, José confecciona seu mapa a partir de um conjunto de hiperlinks, passíveis de acesso. Como já comentado, o ciberespaço possibilita certa variedade de narrativas, inclusive aquelas consideradas não-lineares, inseridas em hiperlinks.

Alves (2005 apud Moita 2007, p. 58) escreve sobre a não-linearidade da narrativa configurada em experiências de jogos eletrônicos que compõem narrativas inseridas em hipertextos. Xavier (2007, p. 107) estuda esse fenômeno como parte de um "gênero da literatura eletrônico-digital", nomeada Ficção Hipertextual. A ideia básica é o rompimento com narrativas lineares por meio do acesso online a vários links de forma concomitante, além da fabricação de enredos e o controle de personagens (XAVIER, 2007, p. 108).

Ele [hiperleitor] topologicamente escolhe os links pelos quais deseja se mover, saltando de um lugar a outro no espaço digital da web, transitando livremente pela narrativa hipertextual de estrutura aberta. Flutuando sobre o hipertexto ficcional, o hiperleitor organiza o enredo de acordo com suas vontades e expectativas, consolidando sua participação real no desvelar da trama virtual. (XAVIER, 2007, p. 107, grifos nossos).

Dando continuidade às carto-falas e aos mapas resultantes das atividades em contexto escolar, passaremos para a apresentação e discussão de enredos com temáticas medievais, característicos de muitos jogos online.

\section{Medievalidade e cartografia}

Quando os/as alunos/as passaram a exprimir suas ideias acerca da criação de mundos fictícios, a referência de parte da turma foi a Idade Média, vista como época de heróis, princesas, 
castelos e aventuras épicas. Essas noções sobre o medievo se conectam à própria história dos jogos eletrônicos, principalmente quando inseridos no contexto da interpretação de personagens, com a criação de enredos e mapas.

Dessa maneira, Jenkins (2004, apud MUSSA, 2011, p. 6) escreve sobre jogos que possuem histórias "evocativas", inspiradas em livros ou filmes. Acrescentamos que, muitas vezes, essas histórias são ambientadas na Idade Média ou num mundo épico com características medievais. Embora na atualidade os já citados MUDs apresentem diversas temáticas, esses jogos se originaram na década de 1970 com clara ambiência medieval, a partir de Dungeons and Dragons, um jogo de interpretação de personagens (WERTHEIM, 2001, p. 171).

Macedo (2009) segue linha de pensamento semelhante, enfatizando que essa ambiência medieval tomou proeminência na década de 1980, época em que "diversos jogos executados em videogames incorporam formas pretensamente medievais aos guerreiros que combatem em reinos distantes, às fortalezas, templos e palácios habitados por guerreiros, magos e feiticeiros" (MACEDO, 2009, p. 17-18).

Com referências da semiótica, Vasconcellos (2005, p. 1) escreve que os "signos medievais" engendrados a partir de filmes e jogos, herdam elementos do medievo a partir da ótica romântica, como ocorre com a temática de "O Senhor dos Anéis" (TOLKIEN, 2001). Aliás, o universo criado por Tolkien será considerado uma inspiração para outros jogos, principalmente aqueles que apresentam dragões e monstros no enredo (MACEDO, 2009, p. 18). Dessa maneira, a "fantasia medieval" ou os mundos medievais virtuais, apresentam leituras românticas da Idade Média.

Macedo (2009, p. 14) distingue o estudo da Idade Média, concebido a partir dos medievalistas, daquelas ideias gerais, muitas vezes confirmadas pelo senso comum, que colocam o medievo "em retrospectiva", como o cinema. Desta última abordagem o autor caracteriza o termo "medievalidade" (MACEDO, 2009, p. 15), englobando os filmes e jogos que inserem a temática medieval apenas como referência, muitas vezes não apresentando rigor histórico.

Nesse sentido, o aluno Mário estabeleceu carto-falas em que a ideia de "medievalidade" está presente:

"Mário: - O meu mapa [Figura 2] ia ficar bonito, sabia? Ia ficar bonito, só que eu não terminei... O meu mapa, por exemplo, eu me inspirei em um dos mapas que você tinha mostrado e é uma mistura das coisas que eu assisto, tal. Eu não consegui terminar mas estava pensando em fazer um reino, estilo uma mistura de Game of Thrones ${ }^{8}$ com outras coisas mais antigas, uma coisa mais... medieval".

\footnotetext{
${ }^{8}$ Alusão à homônima produção televisiva norte-americana, baseada na série de fantasia épica "As Crônicas de Gelo e Fogo", escrita por George R. R. Martin. No site http://wiki.gameofthronesbr.com/index.php/Geografia é possível visualizar a espacialização do mundo fictício proposto pela série. Acesso em 25 out. 2016.
} 


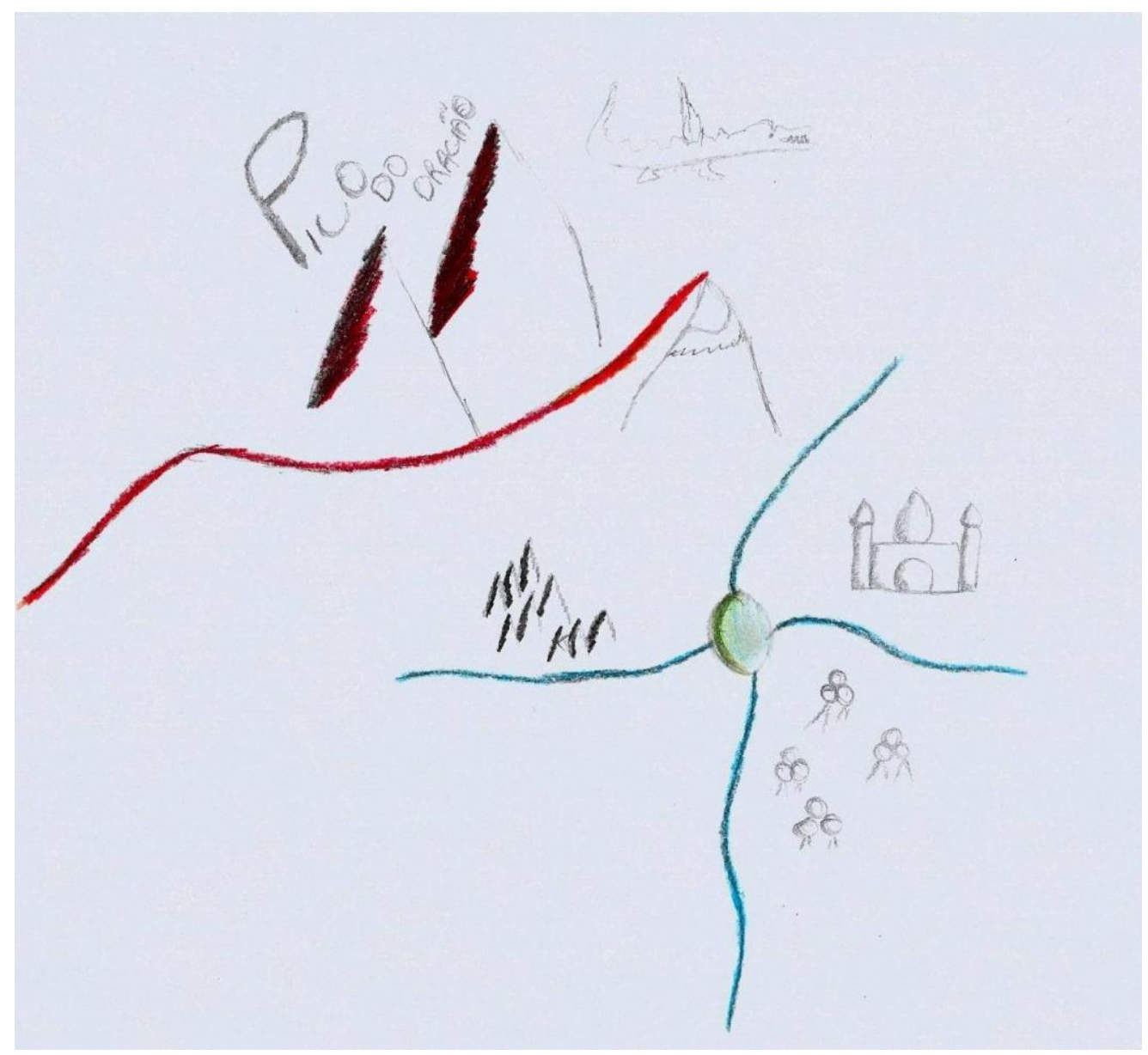

Figura 2 - Mapa do aluno Mário: "Pico do Dragão"

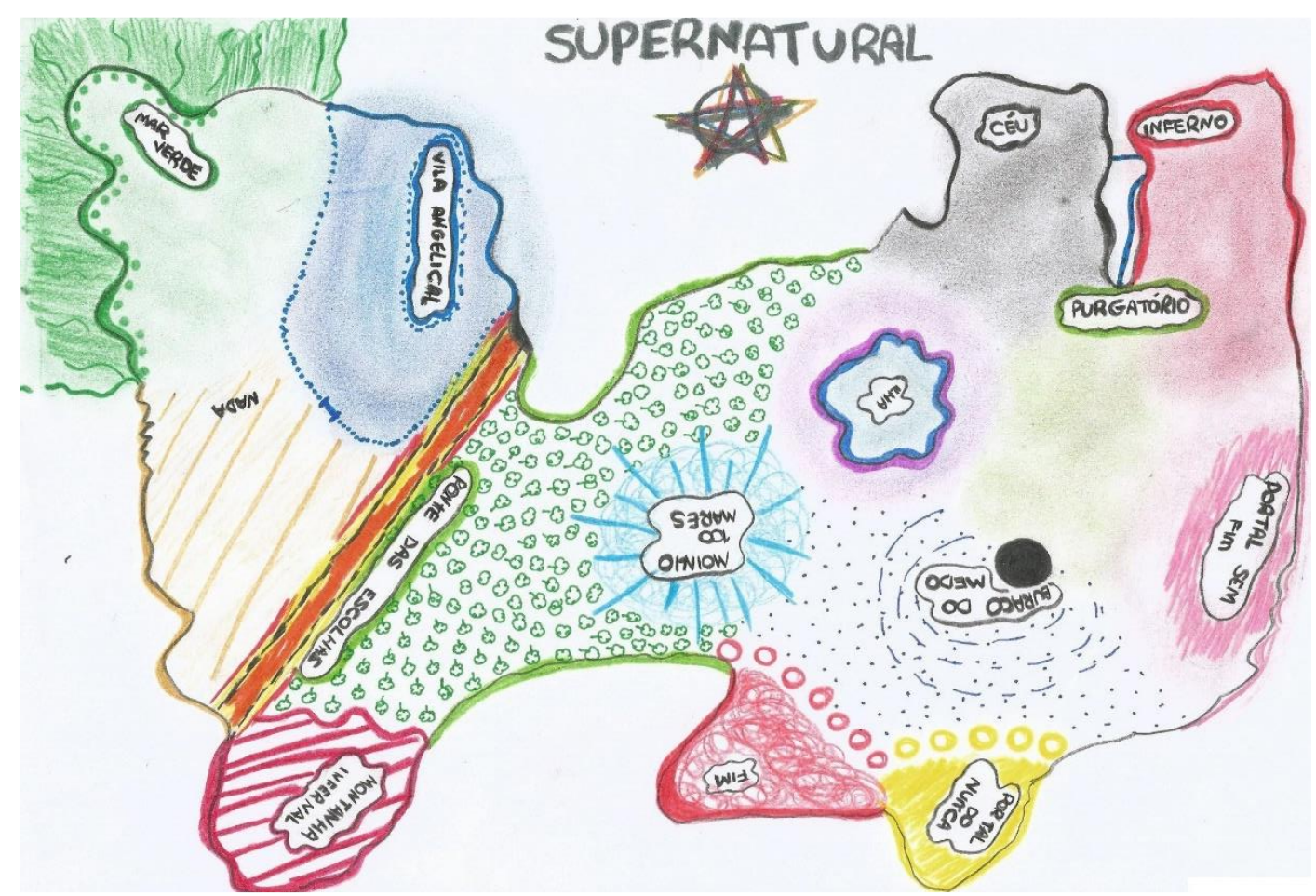

Figura 3: Mapa da aluna Luisa - "Supernatural" 
Outro mapa, "Supernatural" (Figura 3), trabalhava com elementos medievais, como Céu, Inferno e Purgatório 9 . Seguem, abaixo, as carto-falas estabelecidas pela aluna Luisa, autora do mapa.

"Luisa: - Eu fiz isso porque segundo a crença do mapa antigo o céu e o inferno ficavam na Terra. Aí eu desenhei isso porque eu acho que talvez possa ser que fique mesmo e também como esse negócio de navegações porque os mapas serviam para os navegadores saberem o que e onde ficava cada coisa mais ou menos e o que eles iam enfrentar".

Os mapas apresentados são amostras das atividades estabelecidas em contexto escolar e apontam para outras formas de abordagem da cartografia, potencializadas pela inserção de elementos do cotidiano dos/as estudantes. As vivências cotidianas são marcadas, geralmente, pela imersão em jogos e vídeos ligados às narrativas não-lineares, proporcionados em grande medida pelo ciberespaço. As temáticas encontradas envolvem também elementos do medievo, por uma ótica muitas vezes ligada ao romantismo. Dessa maneira, as possibilidades em relação às aulas de cartografia na educação básica se ampliam, incluindo outros tipos de abordagem que merecem mais estudos, como as intervenções artísticas e a confecção de mapeamentos colaborativos online (LEIRIAS, 2012).

\section{Considerações finais}

A imaginação geográfica vai além da ideia de realidade explicada hegemonicamente pela precisão geométrica, que atribui caráter de "transparência" à cartografia. O ciberespaço promove uma ampla gama de atores fazedores de mapas, potencializando a criação de histórias e mundos imaginados coletivamente. Ao longo de nossas atividades na escola ficou nítido o contexto compartilhado pelos/as estudantes, inseridos no ciberespaço. As formas de narrativas não lineares estabelecidas na contemporaneidade podem suscitar outros olhares para a cartografia escolar, com base em hiperlinks, o que traz ao espaço lúdico dos jogos eletrônicos um papel ativo nas criações de cenários e enredos.

\section{Referências}

BAUMAN, Z. Globalização: as consequências humanas. Rio de Janeiro: Zahar, 1999, 145 p.

CARDOSO, E. T. Motivação escolar e o lúdico: o jogo RPG como estratégia pedagógica para ensino de História. 2008. 132 p. Dissertação (mestrado) - Faculdade de Educação. Universidade Estadual de Campinas, Campinas.

CLAVAL, P. Terra dos homens: a geografia. São Paulo: Contexto, 2010. 143 p.

CURIA, D. F. dos S. A Literatura Infanto-juvenil na contemporaneidade: um outro olhar para o literário em sala de aula. Revista Thema, v. 9, n. 2, p. 1-17, 2012. Disponível em: <http://revistathema.ifsul.edu.br/index.php/thema/article/view/134/73 >. Acesso em: 12 dez. 2015.

ESNAOLA, G. A. Claves culturales en la organización del conocimiento: ¿qué enseñan los videojuegos? Buenos Aires: Alfagrama, 2006. 157 p.

\footnotetext{
${ }^{9}$ Esses três elementos medievais foram delineados na obra de Dante Alighieri, “A Divina comédia”, organizada em diversos cantos, dispostos em três livros: Inferno, Purgatório e Paraíso (WERTHEIM, 2001).
} 
GUERREIRO, R. M. B. Sistemas de Informação Geográfica e Videojogos. 2014. 86 p. Dissertação (mestrado) - Instituto Superior de Estatística e Gestão de Informação. Universidade Nova de Lisboa, Lisboa.

KATUTA, A. M. A Geografia, a cartografia, a descrição e a alienação. In: X ENCONTRO DE GEÓGRAFOS DA AMÉRICA LATINA, 10., 2005, São Paulo. Anais... São Paulo, Universidade de São Paulo (USP), 2005. p. 7241-7253.

LEIRIAS, A. G. Novas cartografias on line, arte contemporânea e outras geografias. Geograficidade, v. 2, n. 1, p. 115-133, Número Especial. Primavera, 2012. Disponível em: <http://www.uff.br/posarq/geograficidade/revista/index.php/geograficidade/article/view/59/pdf>.

Acesso em: 23 dez. 2016.

MACEDO, J. R. Introdução - Cinema e Idade Média: Perspectivas de Abordagem. In: MACEDO, J. R.; MONGELli, L. M. de M. (Org.). A Idade Média no cinema. São Paulo: Ateliê, 2009, p. 13-48.

MASSEY, D. B. Pelo espaço: uma nova política da espacialidade. Rio de Janeiro: Bertrand Brasil, 2008, 312 p.

MOITA, F. M. G. da S. C. Game on: jogos eletrônicos na escola e na vida da geração @. Campinas: Alínea, 2007, 194 p.

MURRAY, J. H. Hamlet no Holodeck: o futuro da narrativa no ciberespaço. São Paulo, SP: Editora UNESP: Itaú Cultural, 2003, 282 p.

MUSSA, I. História espacial e os mecanismos de interação nos jogos eletrônicos. In: X SIMPÓSIO BRASILEIRO DE GAMES E ENTRETENIMENTO DIGITAL, 10., 2011, Salvador. Anais... Salvador, Universidade do Estado da Bahia (UNEB), 2011. p. 01-08.

OLIVEIRA, V. H. N. Culturas juvenis e ensino de geografia: da heterogeneidade do jovem contemporâneo às aulas de Geografia. Sl.: Novas Edições Acadêmicas, 2016, 153 p.

SEEMANN, J. Histórias da Cartografia, Imersão em Mapas e Carto-Falas: métodos para estudar culturas cartográficas. In: CAZETTA, V. OLIVEIRA JUNIOR, W. M. de (Org.). Grafias do Espaço: imagens da educação geográfica contemporânea. 1. ed. São Paulo: Átomo \& Alínea, 2013.p. 87-105.

OLIVEIRA, V. H. N. Carto-crônicas: uma viagem pelo mundo da cartografia. Gurupi, TO: Veloso, 2012. $125 \mathrm{p}$.

OLIVEIRA, V. H. N. Entre Usos e Abusos nos mapas da Internet. In: ALMEIDA, Rosângela Doin de (Org.). Novos Rumos da Cartografia Escolar. Currículo, Linguagem e Tecnologia. São Paulo: Contexto, 2011. p. 163-176.

SOUZA, L. S. de. A fantasia e o maravilhoso em $\mathrm{O}$ senhor dos anéis: a sociedade de Tolkien. TEXTURA-ULBRA, v. 15, n. 29, p. 62 - 78, set./dez. 2013. Disponível em: <http://www.periodicos.ulbra.br/index.php/txra/article/view/917/720 >. Acesso em: 10 dez. 2015. 
TOLKIEN, J. R. R. O Senhor dos Anéis. São Paulo: Martins Fontes, 2001. 1202 p.

VASCONCELLOS, M. W. de. Mundos virtuais on-line de temática fantástico-medieval: herança romântica em embalagem tecnológica. I SEMINÁRIO JOGOS ELETRÔNICOS, EDUCAÇÃO E COMUNICAÇÃO - CONSTRUINDO NOVAS TRILHAS, 1., 2005, Salvador. Anais... Salvador, Universidade do Estado da Bahia (UNEB), 2005. p. 01- 24.

WERTHEIM, M. Uma história do espaço de Dante à Internet. Rio de Janeiro: Zahar, 2001. 238 p.

WOOD, Denis. Cartography is dead (thank God!). Cartographic Perspectives, n. 45, p. 04 - 07 , Primavera. 2003. Disponível em: 〈http://makingmaps.owu.edu/mm/cartographydead.pdf>. Acesso em: 12 dez. 2015.

XAVIER, A. C. dos S. Jogos de linguagem em ficção hipertextual: aprendizagem com diversão no ciberespaço. In: SILVA, E. de M.; MOITA, F. M. G. da S. C; SOUSA, R. P. de. (Org.). Jogos Eletrônicos: construindo novas trilhas. 1. ed. Campina Grande: EDUEP, 2007. p. 105-122. 